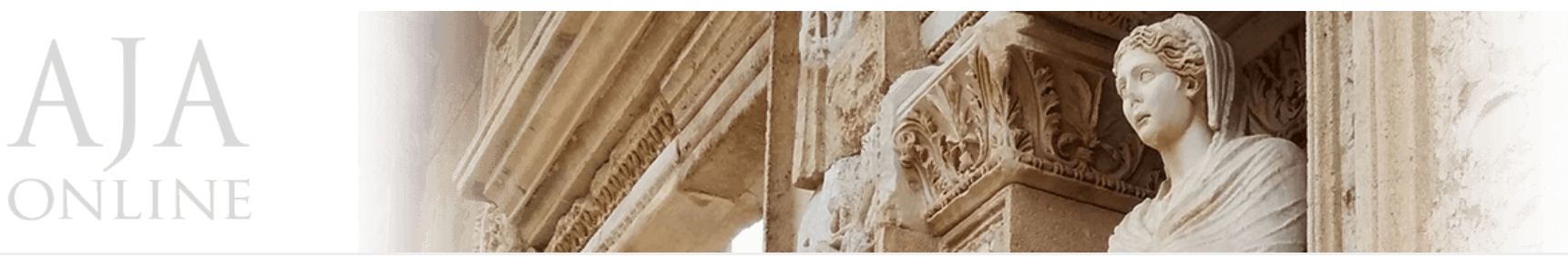

American Journal of Archaeology | The Journal of the Archaeological Institute of America

Home About Subscribe Support the AJA Archive

AJA Open Access $\quad$ Author Guide Learning Resources

July $2015(119.3)$

\title{
ONLINE REVIEW: BOOK
}

\section{Roman Palmyra: Identity, Community, and (c) Br.Nc State Formation}

By Andrew M. Smith II. Pp. xx + 293, figs. 45. Oxford University Press, Oxford 2013. \$85. ISBN 978-0-19-986110-1 (cloth).

Rubina Raja

Studies on Roman Palmyra in the last decade have primarily focused on the archaeology of the city, since the monographs by Kaizer (The Religious Life of Palmyra: A Study of the Social Patterns of Worship in the Roman Period [Stuttgart 2002]) and Yon (Les notables de Palmyre [Beirut 2002]). The excavations by a number of foreign and Syrian missions have been published and added to our knowledge of this fascinating oasis in the Syrian Desert; the work by Michal Gawlikowski and Andreas Schmidt-Colinet has added new perspectives on the development of the city in the Roman period. Palmyra, or Tadmor as the city was also called, has always intrigued scholars of the ancient world. The city's art, architecture, and epigraphy continue to fascinate scholars who work on the Roman Near East because of its richness. However, seldom do Palmyrene history and societal structure receive such detailed attention as they do in Smith's new monograph, which is a reworked version of his doctoral thesis. It is a welcome contribution to studies of Palmyrene society that endeavors to take all new research into account and lay out for us how Palmyrene society developed and which mechanisms were at play in the Roman period, when response to changes in the surrounding world was necessary.

The monograph, which is divided into eight chapters, draws together a vast amount of 
evidence (archaeological, epigraphic, and literary) to tackle the complex issues surrounding the formation of a Palmyrene sedentary society and its development over centuries until the sack of Palmyra in 273 C.E. The titles of the chapters indicate topics covered, but they also highlight the main problems one encounters when working on Palmyrene society, namely that all these spheres in one way or another were intertwined, and that it is hardly possible to separate them from one another. The author is aware of this; however, in the monograph it does cause some repetition from chapter to chapter, since the same evidence has to be mentioned in several places. For example, separating "Tribes and Nomadism" (ch. 2) from "The Growth of Community" (ch. 3) and "The Civic Institutions of Palmyra" (ch. 5) is simply impossible, and therefore repetition becomes necessary. In "Framing the Narrative" (ch. 1), Smith outlines the sources available for understanding Palmyrene society and its development. Among these he importantly mentions the overlooked so-called banqueting tesserae, which present a central body of evidence for, in particular, the structure of religious groups and religious life in Palmyra. He counts 633 inscribed tesserae in the publication by Ingholt, Seyrig, and Starcky from 1955 (Recueil des tessères de Palmyre [Beirut]). Since then, several others have been published that add to our knowledge about these groups. In particular, one must applaud Smith on his chapter on "Tribes and Nomadism"-a fearfully difficult topic to tackle, but he manages to highlight the problems involved when working with societies that were based on family relations. He shows that it is almost impossible to say how large extended families in fact were, and therefore also exactly which implications this had for the societal structure of Palmyrene community. Nonetheless, throughout the monograph he manages to show that Palmyrene families and groups operated on many levels, from that of the "nucleus family" over that of extended families operating across "tribes" to the shaping of civic institutions that still reflected family-based structures, which seem to have remained central throughout the history of Palmyra.

The monograph is an exemplary collection of the written evidence pertaining to the development of Palmyrene society in the Roman period, and it draws on some archaeological evidence as well. It highlights in a clear manner the problems arising from the nature of the evidence that we are dealing with when trying to assert the formation of Palmyrene society and the influence of Roman rule and administration on the city. Since Palmyra offers rich epigraphic evidence, however, of a nature that does not allow for firm conclusions with respect to issues of the tribal structure of the society and the influence of Roman societal structure on the Palmyrene elite, we are left with some speculations that may or may not be supported by the evidence, depending on how one interprets it. Smith shows that the terminology used in inscriptions is not consistent, neither throughout contexts nor throughout time. This is an important observation, since much interpretation of societal structure has been based on terminology used in inscriptions.

However, it is clear from the evidence that the Palmyrene elite was well aware of how Roman social structure functioned and how it could be employed in a local context; they did this nicely in the public sphere, but they also kept their own traditions where they saw fit. Such a strategy should not be interpreted within the framework of "creolization," "romanization," or mixing of traditions, and Smith also avoids doing so. It should be seen within the framework of applying tradition in the spaces and spheres where one saw fit. In the public sphere in Roman Palmyra, a tendency to look as if one has "become Roman" can certainly be traced. The scattered public statuary of Palmyrene citizens, as well as public 
epigraphy, reflect such a tendency in many cases. However, in the funerary sphere we see such influence in neither portraiture nor the inscriptions that accompany many of the funerary reliefs. This is a clear case of such a strategy that does not indicate a separation of spheres, but a high awareness of meaning in situations and contexts. Smith, who does not deal with the evidence from the funerary sphere to any great extent, could have strengthened several arguments through bringing in such evidence in more detail.

The book has a solid and updated bibliography. The quality of the images is generally poor, which is not the fault of the author, but the publisher. Unfortunately, it does have an impact on how one perceives the book. Images are there for a reason, and if a publisher allows them, the publisher should also ensure that they are reproduced in good quality. However, the scholarship offered to us in this book belongs in any research library with an interest in the Roman Near East.

\section{Rubina Raja}

Department of Classical Art and Archaeology

Institute for Culture and Society

Aarhus University

rubina.raja@cas.au.dk

Book Review of Roman Palmyra: Identity, Community, and State Formation, by Andrew M. Smith II Reviewed by Rubina Raja

American Journal of Archaeology Vol. 119, No. 3 (July 2015)

Published online at www.ajaonline.org/online-review-book/2185

DOI: 10.3764/ajaonline1193.Raja 